Fraude no Leite: Experimento Investigativo para o Ensino de Química

\author{
Silva, L. R. R.; Ventura, B.; Almeida, M. O.; Lima, N. M. A.; Silva, K. T.; \\ Maia, F. J. N.; Sampaio, S. G.; Bezerra, T. T.; Guedes, I.; Ribeiro, V. G. P.; \\ Mazzetto, S. E.*
}

Rev. Virtual Quim., 2019, 11 (3), 1024-1043. Data de publicação na Web: 1 de julho de 2019

http://rvq.sbq.org.br

\title{
Milk Fraud: Investigative Experiment for Chemistry Teaching
}

Abstract: In Basic Education, Chemistry contents are considered unattractive by students, who do not even understand chemical phenomena and are unable to associate them with everyday life. In this aspect, the present work aims to research and contextualize experiments as a didactic tool for learning of chemical concepts like density, catalysts, oxidation number, organic functions and chemical reactions to determine adulteration in milk. The research was carried out at the Chemistry Laboratory of the Seara of Science of the Federal University of Ceará (Fortaleza-CE) with high school students. We observed that all students were able to identify adulterations in the milk samples, achieving very satisfactory results. The experiments helped and motivated students in the understanding of chemical concepts, relating them to the reality of the students in their surroundings, from the macroscopic visualization of the chemical knowledge.

Keywords: Experimentation; Chemistry teaching; contextualization; frauds in milk.

\section{Resumo}

Na Educação Básica, os conteúdos de Química são considerados pouco atrativos pelos estudantes, que nem compreendem efetivamente os fenômenos químicos e nem são capazes de associá-los ao cotidiano. Nesse aspecto, o presente trabalho tem como objetivo a elaboração de um experimento, investigativo e contextualizado, como recurso didático para a aprendizagem de conceitos químicos envolvendo densidade, catalisadores, número de oxidação, funções orgânicas e reações químicas na abordagem da temática de fraudes no leite. A pesquisa foi realizada no Laboratório de Química da Seara da Ciência da Universidade Federal do Ceará (Fortaleza-CE), envolvendo alunos do Ensino Médio. Observamos que todos os alunos conseguiram identificar as adulterações nas amostras de leite recebidas, alcançando resultados muito satisfatórios. Os experimentos, além de motivar, auxiliaram na compreensão dos conceitos químicos, relacionando-os com a realidade dos alunos no seu entorno, a partir da visualização macroscópica do conhecimento químico.

Palavras-chave: Experimentação; Ensino de Química; contextualização; fraudes no leite.

\footnotetext{
* Universidade Federal do Ceará, Laboratório de Produtos e Tecnologia em Processos, Departamento de Química Orgânica e Inorgânica, Campus do Pici, CEP 60455-900, Fortaleza-CE, Brazil.

Mselma@ufc.br

DOI: $\underline{10.21577 / 1984-6835.20190069}$
} 


\title{
Fraude no Leite: Experimento Investigativo para o Ensino de Química
}

\author{
Lucas R. R. da Silva, ${ }^{a}$ Bruno Ventura, ${ }^{a}$ Mayara O. de Almeida, ${ }^{a}$ Nayane
} Maria A. Lima, ${ }^{a}$ Kássia T. da Silva, ${ }^{a}$ Francisco J. N. Maia, ${ }^{a}$ Samuel G. Sampaio, ${ }^{a}$ Thayllan T. Bezerra, ${ }^{a}$ Ilde Guedes, ${ }^{b}$ Viviane G. Pereira Ribeiro, ${ }^{c}$ Selma E. Mazzetto ${ }^{a, *}$

a Universidade Federal do Ceará, Laboratório de Produtos e Tecnologia em Processos, Departamento de Química Orgânica e Inorgânica, Campus do Pici, CEP 60455-900, FortalezaCE, Brazil.

b Universidade Federal do Ceará, Seara da Ciência, Rua Abdênago Rocha Lima S/N., Campus do Pici, CEP 60440-614, Fortaleza-CE, Brazil.

c Universidade da Integração Internacional da Lusofonia Afro-Brasileira, Instituto de Ciências Exatas e da Natureza, CEP 62790-000, Redenção-CE, Brazil.

\section{* selma@ufc.br}

Recebido em 25 de fevereiro de 2019. Aceito para publicação em 20 de junho de 2019

\section{Introdução}

1.1. A contextualização no Ensino de Química

1.2. A alimentação como tema gerador

1.3. Experimentação investigativa

1.4. A ANVISA e a fraude nos alimentos

\section{Metodologia}

2.1. Roteiro do experimento "Análise físico-química de controle de qualidade do leite"

2.2. Instrumentos de coleta de dados

\section{Resultados e Discussão}

3.1. Aplicação dos testes investigativos e laudo técnico

3.2. Avaliação da metodologia e grau de aprendizagem

\section{Conclusão}

No Ensino de Química ainda é predominante o método tradicional, no qual os professores transmitem os conteúdos de forma expositiva, apresentando conceitos, 
exemplos e exercícios resolvidos/propostos que pouco estimulam o desenvolvimento dos alunos. ${ }^{1}$ Essa metodologia transmite as informações de forma fragmentada e desconexa da realidade vivida pelos alunos e professores.

A Química presente no cotidiano é um importante instrumento para fazer a ponte entre o conhecimento prévio do aluno e o conhecimento científico. Essa capacidade de associação no ambiente escolar tem sido um dos maiores desafios no Ensino de Química, e tem atraído a atenção para muitas pesquisas nessa área de atuação. ${ }^{2-5}$

É importante compreender que a maneira repetitiva com as quais os princípios, conceitos e fórmulas são ensinados não corroboram de forma satisfatória com a formação de cidadãos capazes de fazer uma análise científica e crítica do meio em que vivem. ${ }^{6} \mathrm{O}$ aprendizado deve ser conduzido levando em consideração as diferentes histórias de vida, o contexto social, os conhecimentos previamente adquiridos e vários outros fatores que os alunos carregam consigo durante a sua formação. A fim de tornar o aprendizado de Química mais simples e prazeroso, tem-se buscado a utilização de diversos recursos didáticos, destacando o cotidiano e a contextualização associados ao Ensino de Química, com metodologias que vão desde o lúdico à experimentação investigativa. $^{7}$

\subsection{A contextualização no Ensino de Química}

Segundo Silva (2003), ${ }^{8}$ embora o conhecimento de Química esteja fortemente inserido no contexto social, político, econômico e cultural, ainda não se apresenta de forma satisfatória para lograr uma aprendizagem significativa. A frequência da seleção, sequenciação e a profundidade dos conteúdos abordados estão sendo aplicados de forma acrítica, mantendo o ensino muitas vezes descontextualizado, dogmático e alheio às necessidades e anseios da comunidade escolar.

Segundo a Base Nacional Comum Curricular $(B N C C)^{9}$, para a formação de indivíduos críticos, criativos, autônomos e responsáveis, é necessário proporcionar experiências que viabilizem uma leitura da realidade para o enfrentamento dos novos desafios da atualidade (sociais, econômicos e ambientais) e a tomada de decisões éticas e fundamentadas, para isto, é fundamental a construção de uma base de conhecimento contextualizado.

Essa contextualização deve ser utilizada como uma ferramenta que realiza aproximações e inter-relações entre o conhecimento adquirido na escola e situações presentes no contexto social dos alunos. Fernandes e Marques $(2015)^{10}$ ressaltam a contextualização como um elemento facilitador da aprendizagem, além de vincular a valorização do cotidiano nas questões aplicadas aos conteúdos. A literatura do Ensino de Ciências apresenta múltiplos significados para a contextualização, caracterizando-a como polissêmica.

No entanto, Wartha et al (2013) $)^{11}$ destacam que muitos professores entendem a contextualização como um recurso onde a aplicação dos conceitos é feita através da exemplificação e da ilustração de contextos no ensino, mas poucos conseguem percebê-la como uma perspectiva na compreensão da realidade social. De um modo geral, contextualizar é problematizar, investigar e interpretar situações, fatos ou fenômenos relevantes para os alunos, utilizando os conceitos de Química de maneira a auxiliá-los na compreensão e na resolução de problemas. $^{8}$

Por fim, a contextualização pode ser atrelada a grandes temas geradores do conhecimento, como chuva ácida, água, rótulos de alimentos, os quais utilizam uma abordagem em Ciência, Tecnologia, Sociedade e Ambiente (CTSA), ${ }^{12-14}$ propiciando aos alunos um entendimento mais significativo dos conteúdos químicos. 


\subsection{A alimentação como tema gerador}

Dentre os diversos temas geradores de saberes, a alimentação é um dos mais ricos conceitualmente, podendo ser trabalhado de forma contextualizada e multidisciplinar, pois permite desenvolver conceitos de Química, Física e Biologia, proporcionando aos estudantes a compreensão de sua importância. ${ }^{15}$

Os alimentos são constituídos por nutrientes caracterizados por funções químicas específicas, estruturas e propriedades físico-químicas particulares que determinam suas funções no organismo.

A Agência Nacional de Vigilância Sanitária - ANVISA, através da Resolução da Diretoria Colegiada - RDC no $360,{ }^{16}$ definiu nutriente como qualquer substância química consumida como componente de um alimento, que proporciona energia necessária ou contribuinte para o crescimento, desenvolvimento e à manutenção da saúde e da vida e, cuja carência possa ocasionar mudanças químicas ou fisiológicas características.

A Química associada ao contexto dos alimentos pode ser considerada uma temática fundamental para o desenvolvimento de diversas propostas didáticas e para a formação cidadã dos estudantes da Educação Básica. ${ }^{2}$ Através dos conteúdos de Química, estes podem ser capazes de compreender a composição química dos alimentos através da rotulagem nutricional e refletir a respeito de seus hábitos alimentares, sob a ótica da ciência. ${ }^{2,15}$

\subsection{Experimentação investigativa}

A experimentação investigativa é considerada uma estratégia didática eficiente na criação de problemas reais que estimulem a motivação, a curiosidade e o interesse dos alunos. ${ }^{17}$ Ela é uma forma de aprendizagem que possibilita os alunos visualizarem, de maneira prática, os conteúdos teóricos vistos em sala de aula, além de poder testá-los. ${ }^{7}$ As atividades experimentais são vistas geralmente com bons olhos, tanto por professores quanto pelos alunos. As mudanças de cores, fumaça e borbulhamentos sempre atraem a atenção dos alunos. ${ }^{18}$

No entanto, o que se observa frequentemente são atividades experimentais orientadas por roteiros pré-determinados realizadas em laboratório, os quais já determinam o que e como fazer. $O$ ensino praticado dessa forma dificulta o raciocínio e os questionamentos acerca do mesmo. ${ }^{19} \mathrm{~A}$ utilização dos experimentos deve promover um caráter investigativo e não apenas ilustrativo, favorecendo a compreensão das relações conceituais da disciplina, onde os alunos possam desenvolver suas hipóteses e aprimorar suas ideias a partir dos seus erros e acertos. $^{2,20}$

A proposta investigativa da experimentação apresenta diferentes possibilidades de se trabalhar e, em geral, pode ser dividida em três níveis, havendo ou não a intervenção do professor durante sua execução e em grau crescente de dificuldade para o aprendiz. Segundo Souza et al. $(2013)^{18}$ existem cinco etapas a serem consideradas em relação aos três níveis de intervenção realizados pelo professor e a respectiva liberdade concedida aos alunos, a saber: (I) proposição do problema, (II) elaboração de hipóteses, (III) elaboração dos procedimentos experimentais, (IV) coleta e análise dos dados e (V) elaboração da conclusão. No nível 1 cabe ao professor propor uma situação-problema, elaborar hipóteses e fornecer os procedimentos experimentais sobre $o$ assunto levantado. Ao aluno cabe a coleta e análise dos dados, assim como a elaboração de uma conclusão, com soluções para o problema em questão. $\mathrm{Na}$ abordagem de nível 2, o professor apenas elabora o problema, as demais etapas são de responsabilidade dos alunos. Por fim, na abordagem de nível 3 , diferentemente das anteriores, cabe ao aluno a elaboração de todas as etapas, de forma a torná-los ativos e 
autônomos no seu próprio processo de ensino-aprendizagem.

0 aspecto investigativo atrelado à experimentação desperta a curiosidade dos estudantes, além de colocá-los diante de situações-problema das quais eles precisam resolver através da coleta de dados, observações, conhecimentos teóricos prévios e criatividade ao propor suas hipóteses, argumentações e explicações. Essa atividade proporciona aos alunos uma participação maior no desenvolvimento da experimentação, acarretando não somente na consolidação dos conceitos teóricos na estrutura cognitiva do educando, mas também na formação de um pensamento científico-crítico. ${ }^{18,19}$

As atividades investigativas devem partir de uma situação-problema que desperte o interesse dos alunos a participar da investigação, de forma a serem motivados em resolvê-la e, ao mesmo tempo, que seja adequado para tratar do conteúdo que se deseja ensinar. ${ }^{21}$ Dessa maneira, os alunos têm um papel ativo no processo de ensinoaprendizagem, onde o professor se torna um orientador, incentivando os alunos a participar, questionando os encaminhamentos dados pelos estudantes na busca da resolução dos problemas e auxiliando na elaboração dos procedimentos e no tratamento dos dados. ${ }^{18}$

Ao planejar uma atividade experimental com caráter investigativo, o professor deve atentar para aspectos que muitas vezes não são considerados ao desenvolver uma atividade que visa somente o conhecimento de fatos ou ilustração de princípios e conceitos já abordados em sala de aula. Entretanto, quando bem planejadas, facilita bastante à compreensão de Química e, contribui significativamente para a construção do conhecimento científico. ${ }^{7}$

\subsection{A ANVISA e a fraude nos alimentos}

A ANVISA tem como finalidade proteger e promover a saúde da população mediante a intervenção nos riscos decorrentes da produção e uso de produtos e serviços sujeitos à vigilância sanitária, em ação coordenada e integrada no âmbito do Sistema Único de Saúde (SUS). ${ }^{22}$ Sua atuação abrange muitas atividades que vão desde a fiscalização de estabelecimentos a irregularidades que apresentam riscos à saúde. A regulamentação e a fiscalização de alimentos, agrotóxicos, medicamentos, cosméticos e saneantes são algumas das áreas nas quais a vigilância sanitária atua. ${ }^{23}$

As pessoas diariamente consomem vários produtos e utilizam diversos serviços que necessitam de critérios de segurança para evitar ameaças à saúde. A vigilância sanitária trabalha exatamente para fornecer a população a segurança e a qualidade desses produtos e serviços.

Na área de alimentos, a ANVISA coordena, supervisiona e controla as atividades de registro, informação, inspeção, controle de riscos e estabelecimento de normas e padrões de qualidade. Ela realiza em todo o país o controle e a fiscalização de produtos alimentícios por meio de amostras de alimentos expostos no comércio. ${ }^{23,24}$

A análise laboratorial dessas amostras é executada pelos Laboratórios Centrais de Saúde Pública dos Estados (Lacens), os quais possuem uma divisão de bromatologia (do grego bromatos $=$ alimentos e logos $=$ estudo) responsável por tais análises. Nestes laboratórios, as amostras são avaliadas por meio da verificação de parâmetros físicoquímicos, microbiológicos, presença de aditivos e outros contaminantes. Além disso, também são analisadas as informações de rotulagem obrigatória e, se o que consta no produto está de fato em conformidade com o declarado no seu rótulo. ${ }^{24}$

Mais precisamente, nestes laboratórios são realizadas investigações acerca da composição química dos alimentos, como 
carboidratos, lipídeos, proteínas e minerais. Em casos específicos, buscam-se determinar alguns componentes individuais como metais pesados (chumbo e mercúrio), açúcares (lactose), aminoácidos específicos (fenilalanina e lisina), dentre outros. Os resultados obtidos através das análises desses componentes são utilizados para a verificação da eficiência do processo e da qualidade dos alimentos, da segurança alimentar, e fornecer informações de importância nutricional sobre os alimentos disponibilizados à população. ${ }^{25}$

A rotulagem de todos os alimentos é regulamentada pela resolução RDC 259/02 da ANVISA, onde apresenta seis itens de declaração obrigatória: lista de ingredientes (com todos os ingredientes contidos nos alimentos, incluindo aditivos alimentares), conteúdo líquido, origem, lote, prazo de validade e designação do produto. Além disso, através da resolução RDC 360/03 se tornou obrigatório a declaração da quantidade do valor energético e dos seguintes nutrientes: carboidratos, proteínas, gorduras totais, gorduras saturadas, gorduras trans, fibra alimentar e sódio. ${ }^{24}$

Em fevereiro de 2017 a Agência publicou novas regras para a rotulagem de produtos com lactose. A primeira foi a RDC 135/2017, onde incluiu os alimentos para dietas com restrição à lactose em regulamento destinado a alimentos para fins especiais. A segunda foi a RDC 136/2017, que definiu como as informações sobre lactose devem ser apresentadas nos rótulos, independentemente do tipo de alimento. ${ }^{26}$

No entanto, apesar de toda essa regulamentação e fiscalização, ainda são recorrentes casos de fraudes de alimentos como carnes, peixes, leites, dentre outros. A qualidade dos alimentos é uma preocupação mundial, sendo necessária a fiscalização constante como medida de segurança contra produtos fraudados e de qualidade inferior em relação aos já existentes no mercado. ${ }^{27}$

Nas indústrias de laticínios, os principais prejuízos causados pelas fraudes são a diminuição no valor nutricional, a alteração na qualidade do produto e o risco aos consumidores em virtude da presença de substâncias estranhas, as quais podem prejudicar à saúde, tais como os agentes antimicrobianos (antibióticos), os conservantes (peróxido de hidrogênio $/ \mathrm{H}_{2} \mathrm{O}_{2}$ ), neutralizantes (bicarbonato de sódio/ $\mathrm{NaHCO}_{3}$ e hidróxido de sódio/ $\mathrm{NaOH}$ ), os reconstituintes de densidade e a crioscopia (sal, açúcar, amido). ${ }^{27}$

Considerando a importância da contextualização em despertar o interesse dos educandos para a aprendizagem de conceitos químicos e o papel da experimentação investigativa na construção do conhecimento científico, utilizamos neste trabalho estas duas ferramentas de ensino, em sala de aula e no laboratório, para investigar possíveis fraudes no leite.

\section{Metodologia}

Este trabalho foi realizado em 2017 durante o Curso básico de Química experimental da Seara da Ciência da Universidade Federal do Ceará (UFC). A Seara da Ciência é o órgão de Divulgação Científica e Tecnológica da UFC, que atua desde o ano 2000 com o objetivo de popularizar a Ciência e colaborar com melhorias no Ensino de Ciências no Estado do Ceará. Para isso, desenvolve diversas ações em diferentes linguagens, direcionadas aos estudantes dos níveis fundamental e médio de escolas públicas e particulares do estado, além da população em geral.

Dentre suas ações destacam-se a manutenção do Salão de Exposições, com shows científicos; promoção de cursos básicos (Química, Física, Biologia, Astronomia e Matemática) e de férias; feiras de ciências; criação, montagem e apresentação de peças de teatro científico; página na internet e assessorias a outros centros de divulgação científica espalhados pelo Brasil e também no exterior. Sobre os cursos básicos, estes existem desde a fundação da instituição e são 
ofertados semestralmente aos alunos da rede pública do município e região metropolitana de Fortaleza.

O presente trabalho foi desenvolvido em duas turmas do curso citado, nos períodos da manhã e tarde, com limitação de 20 alunos/turno, para garantir uma acomodação adequada e segura para os alunos ao executar suas atividades experimentais no laboratório.

O estudo consistiu em elaborar um experimento investigativo (nível 1) e contextualizado para identificar adulterações em amostras de leite. $O$ procedimento ocorreu em quatro etapas: (1) inicialmente, foi realizada uma pesquisa sobre o campo de atuação da ANVISA e quais técnicas experimentais são empregadas nas análises em alimentos, especificamente o leite, de modo a selecionar quais teriam o maior potencial de reprodução/adaptação para os alunos; (2) foram elaborados um conjunto de experimentos práticos que envolvessem os conteúdos de densidade, número de oxidação, catalisadores, funções orgânicas e reações químicas; (3) posteriormente, foi ministrada uma aula teórica aos estudantes que antecedeu a experimentação, onde foram trabalhados vários assuntos como: (a) a importância da rotulagem e da qualidade dos alimentos, em particular do leite; (b) as funções da ANVISA e os tipos de fraudes alimentares recorrentes no país, e quais as técnicas utilizadas pelo órgão na fiscalização do leite; (c) conteúdos químicos que objetivassem resgatar o cotidiano dos alunos dentro do tema da adulteração em alimentos; (4) por fim, os alunos foram para o laboratório de química, divididos em grupos de quatro alunos em cada bancada, para a realização dos experimentos investigativos. Cada equipe foi acompanhada durante todo o transcorrer dos experimentos por dois dos autores do trabalho, com o objetivo de auxiliar na compreensão dos passos experimentais, manipulação das vidrarias e questionamentos levantados pelo grupo.

A medida em que os resultados experimentais foram levantados, um laudo técnico similar aos padrões da ANVISA, foi preenchido para posterior verificação das adulterações nas amostras de leite fornecidas. Cada grupo recebeu uma amostra padrão de leite (referência) e amostras com diferentes adulterações (adição de peróxido de hidrogênio, adição de amido, excesso de água e teor de lactose). As contaminações eram as mesmas para cada grupo, porém o lote era diferente. Dessa forma, necessitavam realizar todos os experimentos para encontrar o tipo de adulteração de cada lote.

A atividade experimental foi elaborada considerando as orientações de Souza et al (2013), ${ }^{18}$ em relação aos níveis de intervenção feita pelo professor e liberdade concedida aos alunos. Nesta proposta de trabalho cabe ao professor propor uma situação-problema, fornecer os procedimentos experimentais e elaborar hipóteses sobre o assunto levantado. Ao aluno coube à coleta e análise dos dados, e a elaboração de uma conclusão com soluções para o problema em questão.

O caráter investigativo da referida experimentação foi desenvolvido com base em uma história fictícia (Figura 1) de alunos e funcionários que foram acometidas de um mal-estar ao fazerem um lanche na escola. Com isso, inspetores da vigilância sanitária decidiram fiscalizar o local e as marcas de leite da região que faziam a distribuição nas escolas. Diante do caso, os alunos atuariam como agentes da ANVISA e analistas químicos. 


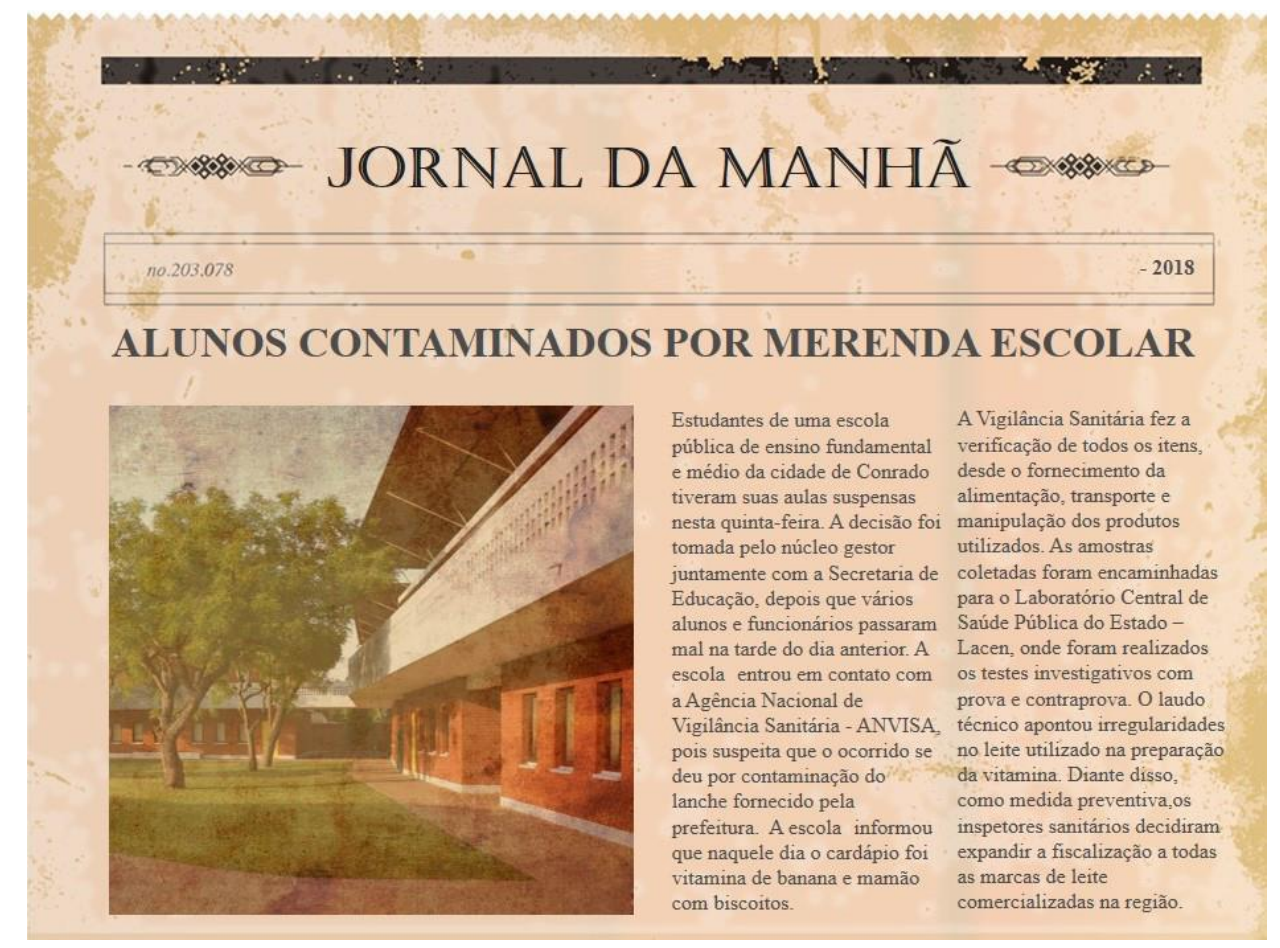

Figura 1. História fictícia envolvendo a situação-problema

As amostras de leite a serem analisadas representavam quatro diferentes marcas de leite integral, nomeadas de A, B, C e D. Cada rótulo continha data de validade, lote, data de fabricação e densidade (Figura 2). Para efeito de comparação, foi fornecido uma amostra de referência (R). Cada amostra foi anteriormente adulterada com um tipo de contaminante, podendo ser amido, peróxido de hidrogênio, glicose e/ou galactose e água.

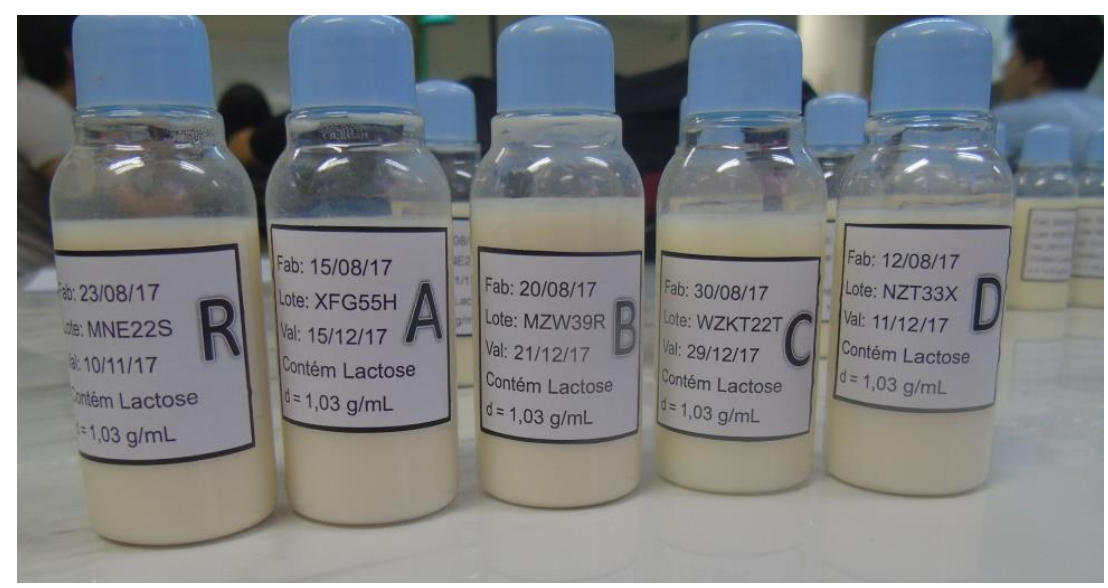

Figura 2. Amostras de leite analisadas no experimento

Antes do início das análises investigativas, foram fornecidas instruções a respeito do manuseio das vidrarias de laboratório (pipetas, tubos de ensaio e proveta). Em sequência, cada grupo teria que obrigatoriamente realizar uma amostragem seguida dos testes de densidade, identificação de amido, lactose e peróxido de hidrogênio. 0 processo de amostragem teve como objetivo obter uma pequena parte que representasse 
o todo da amostra principal, pois se realizado de maneira incorreta os procedimentos seguintes poderiam gerar resultados não confiáveis. Portanto, solicitou-se aos grupos que antes de qualquer coisa agitassem bastante por inversão cada amostra.

2.1. Roteiro do experimento "Análise físico-química de controle de qualidade do leite"

Materiais utilizados: tubos de ensaio, pipeta Pasteur, chapa aquecedora, pinça de madeira, proveta de $10 \mathrm{~mL}$ e as amostras de leite. Reagentes: solução de Benedict, solução de iodo $2 \%$, solução de iodeto de potássio (KI)
$2 \%(\mathrm{~m} / \mathrm{v})$, detergente e água destilada. Procedimento experimental a seguir:

\section{Determinação da densidade}

1) Pese uma proveta de $10 \mathrm{~mL}$ vazia $\left(P_{1}\right)$, anote o valor e retorne a sua bancada;

2) Com o auxílio de uma pipeta graduada adicione $10 \mathrm{~mL}$ da amostra de referência $(R)$ na proveta anteriormente pesada e pese novamente anotando o valor $\left(\mathrm{P}_{2}\right)$;

3) Repita esse procedimento para as demais amostras (A, B, C e D);

4) Calcule a densidade de acordo com a equação:

$$
d=\frac{\text { Mass } a}{\text { Volume }}, \text { onde a massa }=\mathrm{P}_{2}-\mathrm{P}_{1}
$$

\begin{tabular}{lccc}
\hline AMOSTRAS & $\begin{array}{c}\text { MASSA DA } \\
\text { PROVETA } \\
\text { VAZIA }\left(\mathbf{P}_{1}\right)\end{array}$ & $\begin{array}{c}\text { MASSA DA PROVETA } \\
\text { CONTENDO 10 ML DE } \\
\text { LEITE }\left(\mathbf{P}_{2}\right)\end{array}$ & $\begin{array}{c}\text { DIFERENÇA } \\
\text { DAS MASSAS } \\
\left(\mathbf{P}_{2}-\mathbf{P}_{1}\right)\end{array}$ \\
\hline REFERÊNCIA & & & \\
AMOSTRA A & & & \\
AMOSTRA B & & & \\
AMOSTRA C & & & \\
AMOSTRA D & & & \\
\hline
\end{tabular}

\section{Contaminação por amido}

1) Enumere cinco tubos de ensaio (1 a 5).

2) Com o auxílio de uma pipeta Pasteur, adicione $1,0 \mathrm{~mL}$ da amostra de referência $(\mathrm{R})$ no tubo 1;

3) Em seguida, adicione $3,0 \mathrm{~mL}$ de água e agite por 30 segundos;

4) Adicione 3 gotas da solução de iodo $2 \%$ no tubo 1 . Se a amostra estiver contaminada com amido, aparecerá uma coloração azul ou roxa. Anote o resultado;
5) Repita esse procedimento para as demais amostras (A, B, C e D).

III. Rotulagem incorreta (informou que contém Lactose)

1) Enumere cinco tubos de ensaio (1 a 5).

2) Com o auxílio de uma pipeta Pasteur, adicione $1,0 \mathrm{~mL}$ da amostra de referência $(\mathrm{R})$ no tubo 1 ;

3) Adicione ao tubo 1 mais $3,0 \mathrm{~mL}$ de água e $1,0 \mathrm{~mL}$ da solução de Benedict. Em 
seguida agite o tubo de ensaio por 30 segundos;

4) Aqueça o tubo em banho-maria por 6 minutos e observe se ocorre alteração de cor. Anote o resultado;

5) Repita esse procedimento para as demais amostras (A, B, C e D).

\section{Contaminação por peróxido de hidrogênio}

1) Enumere cinco tubos de ensaio (1 a 5).

2) Com o auxílio de uma pipeta Pasteur, adicione $1,0 \mathrm{~mL}$ da amostra de referência $(R)$ no tubo 1;

3) Em seguida, adicione 3 gotas de detergente e 3 gotas da solução de KI 2 \% (m/v) no tubo 1 e espere cerca de 5 minutos;

4) Se a amostra estiver contaminada com peróxido de hidrogênio será observado um aumento na formação de espuma e borbulhamento. Anote o resultado;

5) Repita esse procedimento para as demais amostras (A, B, C e D).

\subsection{Instrumentos de coleta de dados}

Após o término das análises experimentais cujo objetivo era descobrir qual a contaminação de cada amostra, os alunos foram orientados a preencher o laudo técnico, estruturado com base no documento fornecido pelo Lacen com adaptações. O laudo foi dividido em três partes (Figura 3). A primeira consistia na identificação dos analistas seguido da referência da amostra analisada, como lote, validade e fabricação. $\mathrm{Na}$ segunda parte, os estudantes marcaram positivo ou negativo conforme a análise realizada e o resultado obtido através dela. $\mathrm{Na}$ terceira parte, foi solicitado que anotassem suas observações sobre as análises executadas. Por fim, cada equipe deveria expressar suas conclusões referentes às amostras de leite recebidas.

Finalmente, aplicou-se um questionário composto por 5 questões abertas com o objetivo de avaliar o grau de aceitação da metodologia utilizada e o nível de aprendizagem dos alunos em relação aos conteúdos abordados, a saber: (1) Você já tinha realizado experimentos envolvendo alimentos? Se sim, comente; (2) O que você achou da utilização de experimentos investigativos como forma de aprendizagem?; (3) Aponte, segundo os seus conhecimentos sobre a Química, quais assuntos você assimilou com a realização dos testes investigativos?; (4) Você considera importante saber a qualidade dos alimentos que está consumindo? Por quê?; (5) Você sentiu dificuldades na realização dos testes investigativos? Onde? 


\begin{tabular}{|c|c|c|c|c|c|}
\hline \multicolumn{6}{|c|}{ Laudo Técnico - Análises Físico-Químicas de Controle de Qualidade do Leite } \\
\hline \multicolumn{6}{|l|}{ Analistas: } \\
\hline Produto & $\mathrm{R}$ & A & B & $\mathrm{C}$ & $\mathrm{D}$ \\
\hline \multicolumn{6}{|l|}{ Validade } \\
\hline \multicolumn{6}{|l|}{ Lote } \\
\hline Fabricação & & & & & \\
\hline
\end{tabular}

\begin{tabular}{|c|c|c|c|c|}
\hline \multicolumn{5}{|c|}{ Análises e Resultados } \\
\hline \multirow{2}{*}{ Testes Realizados } & \multirow{2}{*}{ Amostras } & \multicolumn{2}{|c|}{ Resultado } & \multirow{2}{*}{ Observações } \\
\hline & & Positivo & Negativo & \\
\hline \multirow{4}{*}{$\begin{array}{c}\text { Aspecto } \\
\text { (cor, odor, consistência e } \\
\text { sedimentação) }\end{array}$} & A & ( ) & ( ) & \\
\hline & B & $(\quad)$ & $(\quad)$ & \\
\hline & $\mathrm{C}$ & $(\quad)$ & $(\quad)$ & \\
\hline & D & $(\quad)$ & $(\quad)$ & \\
\hline \multirow{4}{*}{ Densidade } & $\mathrm{A}$ & $(\quad)$ & $(\quad)$ & \\
\hline & B & () & $(\quad)$ & \\
\hline & $\mathrm{C}$ & $(\quad)$ & $(\quad)$ & \\
\hline & $\mathrm{D}$ & () & $(\quad)$ & \\
\hline \multirow{4}{*}{ Amido } & A & ( ) & ( ) & \\
\hline & B & ( ) & ( ) & \\
\hline & $\mathrm{C}$ & $(\quad)$ & $(\quad)$ & \\
\hline & $\mathrm{D}$ & $(\quad)$ & ( ) & \\
\hline \multirow{4}{*}{ Lactose } & $\mathrm{A}$ & $(\quad)$ & $(\quad)$ & \\
\hline & B & ( ) & ( ) & \\
\hline & $\mathrm{C}$ & $(\quad)$ & $(\quad)$ & \\
\hline & $\mathrm{D}$ & $(\quad)$ & $(\quad)$ & \\
\hline \multirow{4}{*}{ Peróxido de Hidrogênio $\left(\mathrm{H}_{2} \mathrm{O}_{2}\right)$} & $\mathrm{A}$ & $(\quad)$ & $(\quad)$ & \\
\hline & B & $(\quad)$ & $(\quad)$ & \\
\hline & $\mathrm{C}$ & $(\quad)$ & $(\quad)$ & \\
\hline & $\mathrm{D}$ & $(\quad)$ & $(\quad)$ & \\
\hline \multicolumn{5}{|l|}{ Conclusão } \\
\hline
\end{tabular}

Figura 3. Laudo técnico utilizado pelos grupos no parecer da qualidade das amostras de leite 


\section{Resultados e Discussão}

\subsection{Aplicação dos testes investigativos e laudo técnico}

As investigações foram iniciadas analisando aspectos como coloração, consistência e sedimentação das amostras, em comparação com a amostra referência, considerando que o primeiro contato entre o consumidor e o produto, geralmente se dá pela aparência visual, onde se destacam esses parâmetros. Alguns alunos relataram que determinada amostra tinha coloração mais clara, outros disseram que a cor do leite estava amarelada, enquanto que outro grupo observou que havia sedimentação na amostra (Figura 4). A este respeito, Teixeira (2009) ${ }^{28}$ destaca que todos os produtos possuem uma aparência e cor esperadas, associadas às reações pessoais de aceitação, indiferença ou rejeição em relação a determinado produto.

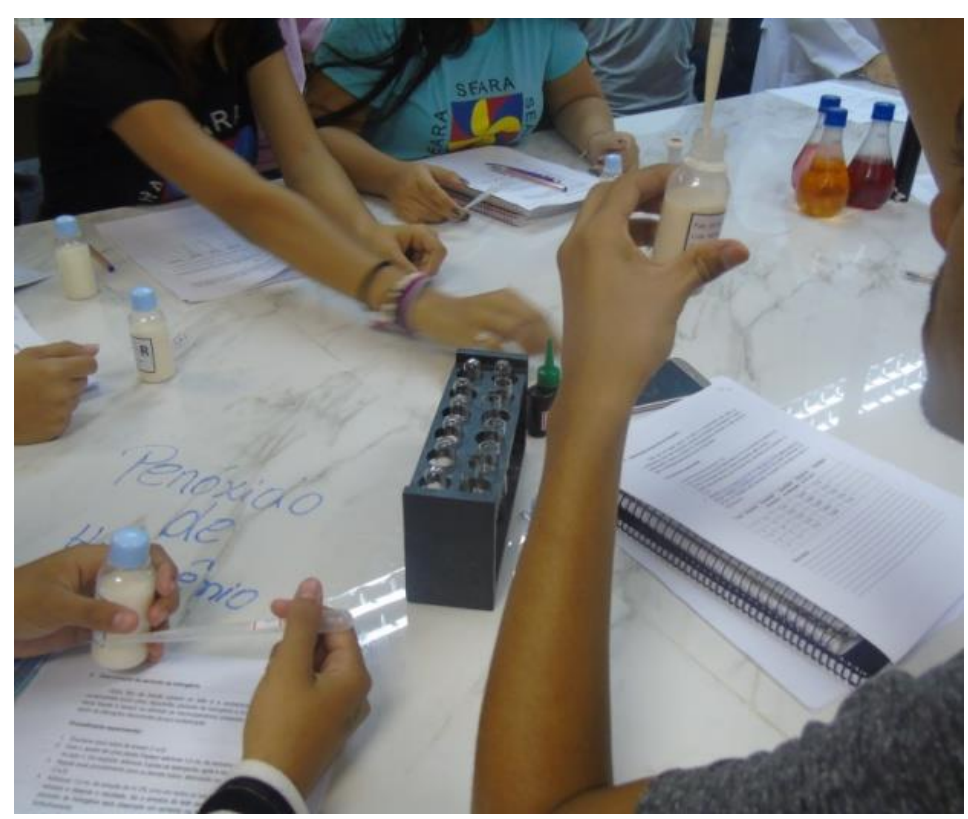

Figura 4. Observações iniciais feitas pelos alunos

Em seguida, o teste da densidade foi realizado, por ser uma das maneiras mais fáceis de detectar fraudes no leite. As amostras A, B, C, D e R foram submetidas ao referido teste, no qual os alunos concluíram quais haviam maior ou menor densidade, comparadas a do leite referência ( $R$ ). A Tabela 1 apresenta os resultados obtidos por um dos grupos.

Tabela 1. Resultados do teste de densidade (Grupo 1)

\begin{tabular}{cl}
\hline Amostras & Densidade \\
\hline (R) & $1,03 \mathrm{~g} \mathrm{~mL}^{-1}$ \\
A & $1,04 \mathrm{~g} \mathrm{~mL}^{-1}$ \\
B & $1,05 \mathrm{~g} \mathrm{~mL}^{-1}$ \\
C & $1,03 \mathrm{~g} \mathrm{~mL}^{-1}$ \\
D & $1,01 \mathrm{~g} \mathrm{~mL}^{-1}$ \\
\hline
\end{tabular}

$\mathrm{R}=$ Referência (leite sem contaminação) 
Todos os grupos conseguiram concluir que as amostras A e B apresentavam densidade maior que a referência e a amostra $D$ menor. De acordo com o laudo dos alunos, a amostra D foi contaminada com adição de água, pois sua densidade era inferior à da amostra de referência e se aproximava à da água cujo valor é de $1,00 \mathrm{~g} \mathrm{~mL}^{-1}$. Segundo Abrantes et al $(2014)^{27}$ a principal fraude detectada no leite ainda continua sendo a adição de água com o intuito de aumentar seu volume, cuja presença de água pode ser percebida pela redução da densidade. Além disso, a densidade, apesar de ser considerada um conceito simples, é de fundamental importância para o aprendizado de Química, visto que pode ser utilizada tanto para a caracterização das substâncias quanto na compreensão de situações mais complexas. ${ }^{29}$ Aqui os estudantes puderam visualizar a aplicação deste conceito na resolução de um problema do dia a dia.

O segundo teste realizado pelos estudantes foi para identificar se 0 contaminante era o amido. Para isso, os alunos observaram a mudança de coloração de branco para azul das amostras em relação à referência, o que garante teste positivo (Figura 5). No laudo os alunos relataram que a amostra A estava contaminada com amido, pois ao adicionarem algumas gotas de iodo a coloração mudou ligeiramente para o azul enquanto as demais ficaram amarelas.

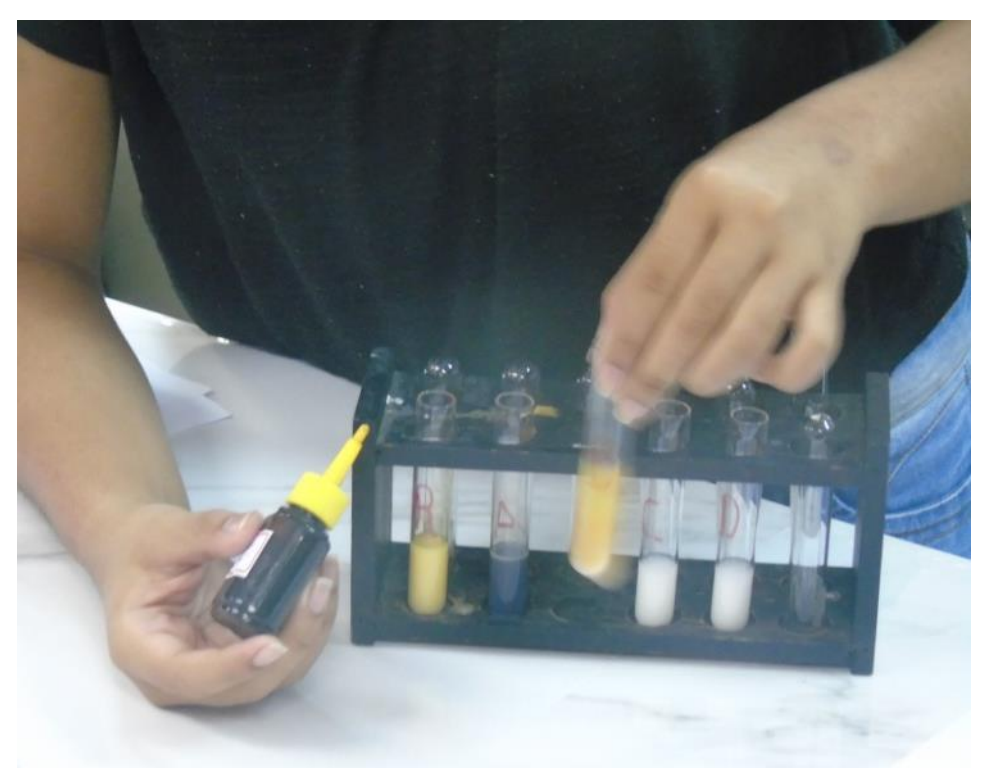

Figura 5. Teste do amido

O amido é um polímero de glicose encontrado nos vegetais. É composto por duas cadeias, a amilose e a amilopectina. A coloração observada é devido ao aprisionamento do iodo no interior da cadeia de amilose formando um complexo. A incorporação de reconstituintes, no caso o amido, é usada para mascarar a adição de água ao leite e promover uma diluição dos seus componentes, reduzindo seu valor nutricional. ${ }^{30}$ Embora as reações de complexação não façam parte do currículo do ensino médio, o professor pode abordá-las dentro do assunto de reações químicas associando à mudança de cor como um indício de reação, por exemplo. Alguns autores sugerem ainda que a discussão do teste pode ser utilizada para introduzir o tema polímeros, assim como os diferentes tipos de açúcares (monossacarídeo, dissacarídeo e polissacarídeo). ${ }^{31}$

O terceiro teste realizado foi $\mathrm{o}$ de identificação do peróxido de hidrogênio $\left(\mathrm{H}_{2} \mathrm{O}_{2}\right)$. O borbulhamento e crescimento de uma espuma de cor amarela no tubo de ensaio indicava o resultado positivo para o 
referido teste (Figura 6). De acordo com o laudo dos alunos, a amostra B estava contaminada com $\mathrm{H}_{2} \mathrm{O}_{2}$, pois foi a única amostra que produziu, após alguns segundos, bastante espuma no tubo de ensaio.

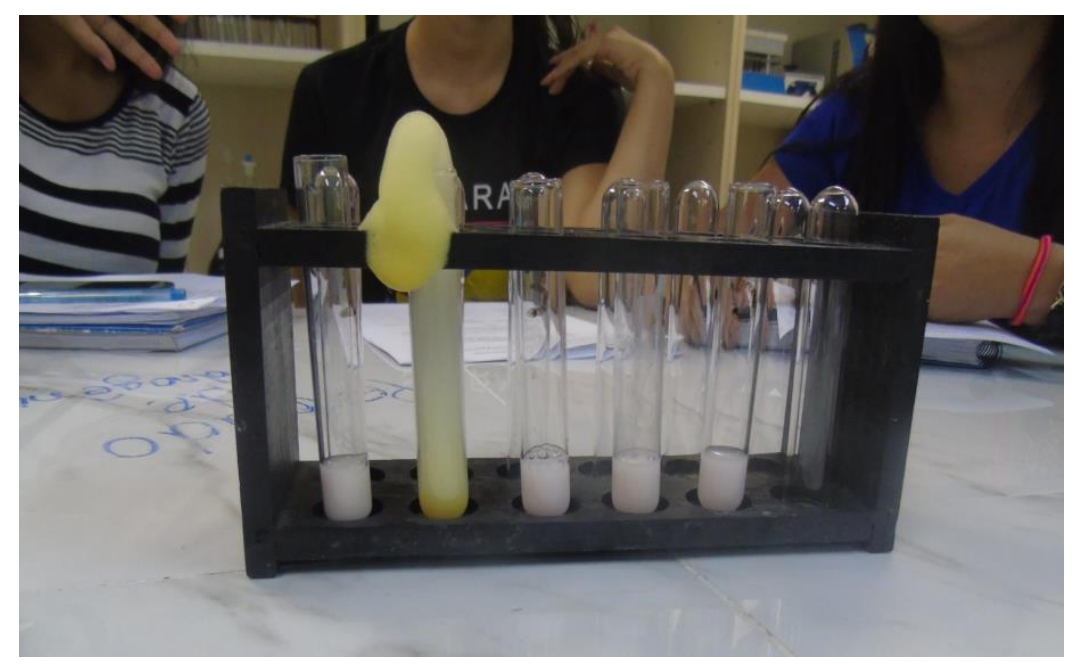

Figura 6. Teste do peróxido de hidrogênio

O peróxido de hidrogênio se decompõe espontaneamente a temperatura ambiente, de acordo com a equação (1):

$$
2 \mathrm{H}_{2} \mathrm{O}_{2(a q .)} \rightarrow 2 \mathrm{H}_{2} \mathrm{O}_{(l)}+\mathrm{O}_{2(g)}
$$

Essa reação de decomposição pode ser acelerada por aquecimento ou ainda a temperatura ambiente na presença de um catalisador, que nesta prática fez uso do KI. A cinética da reação é dada pelas seguintes equações (2) e (3):

$$
\begin{aligned}
\mathrm{H}_{2} \mathrm{O}_{2(a q .)}+\mathrm{I}_{(a q .)}^{-} & \rightarrow \mathrm{H}_{2} \mathrm{O}_{(l)}+\mathrm{IO}_{(\text {aq. })}^{-} \\
\mathrm{H}_{2} \mathrm{O}_{2(a q .)}+\mathrm{IO}_{(a q .)}^{-} & \rightarrow \mathrm{H}_{2} \mathrm{O}_{(l)}+\mathrm{O}_{2(a q .)}+I_{(a q .)}^{-}
\end{aligned}
$$

A formação de bolhas e o crescimento da espuma ocorrem devido a rápida formação de oxigênio gasoso, proveniente da decomposição do peróxido, que se torna mais notória pela adição do detergente. $O$ peróxido de hidrogênio pode ser adicionado de forma fraudulenta ao leite com a função de prevenir a proliferação de microrganismos e prolongar sua vida útil. Os microrganismos provocam a hidrólise da lactose com a produção de ácido lático. Com o aumento da acidez, a caseína precipita, tornando-o impróprio para o consumo. ${ }^{32} \mathrm{~A}$ utilização deste teste permitiu trabalhar o conteúdo de cinética química, abordando fatores que influenciam na velocidade das reações, como o uso de catalisadores; fenômenos químicos como a efervescência de comprimidos, corrosão, conservação de alimentos, que ocorrem no cotidiano dos alunos.

O último teste realizado foi o da lactose, cujo objetivo foi identificar se o leite era 
integral ou sem lactose. Neste, os alunos constataram na amostra $\mathrm{C}$ a presença de galactose e glicose ao invés de lactose através da mudança de cor da solução de Benedict ${ }^{33}$ do azul para o amarelo (Figura 7). Os alunos tiveram muitas dificuldades na realização deste teste, pois caso ultrapasse o tempo de aquecimento necessário, pode-se obter um falso positivo.
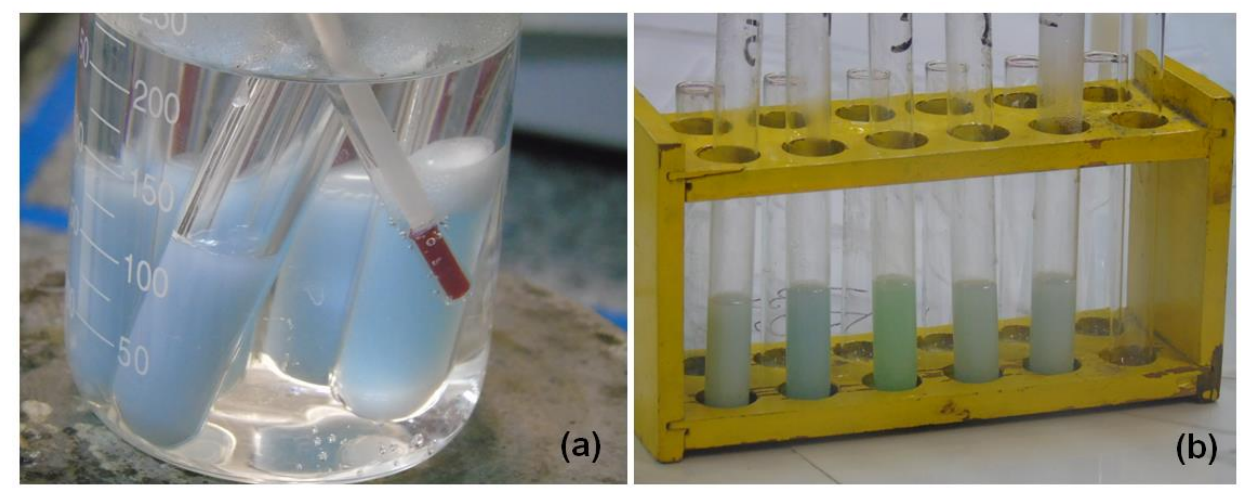

Figura 7. Teste de lactose. (a) Durante o aquecimento e (b) Após o aquecimento

Os monossacarídeos apresentam dupla função orgânica (aldeído e álcool ou cetona e álcool). Devido ao poder redutor das carbonilas, em solução alcalina, o íon $\mathrm{Cu}^{2+}$ (azul) foi reduzido a íon $\mathrm{Cu}^{1+}$ (amarelo).

A coloração inicial do regente Benedict é azul (solução de $\mathrm{CuSO}_{4}$ em meio básico). $\mathrm{Na}$ presença de um agente redutor, após aquecimento, observa-se o aparecimento de coloração castanha e/ou precipitado de mesma coloração. ${ }^{33}$ Essa coloração varia do azul ao castanho, dependendo da quantidade de agente redutor, que neste experimento são os açúcares. A reação que descreve esse fenômeno é demonstrada pela equação (4):

$$
2 \mathrm{Cu}_{(a q .)}^{2+}+4 \mathrm{OH}_{(\text {aq. })}^{-}+\mathrm{RCHO}_{(\text {aq. })} \stackrel{\Delta}{\rightarrow} \mathrm{RCOOH}_{(a q .)}+\mathrm{Cu}_{2} \mathrm{O}_{(s)}+2 \mathrm{H}_{2} \mathrm{O}_{(l)}
$$

Os açúcares com capacidade de reduzir o íon $\mathrm{Cu}^{2+}$ são chamados de açúcares redutores, sendo os mais comuns a glicose, a frutose e a galactose (Figura 8). Vale ressaltar que a lactose também pode dar positivo neste teste, pois dependendo da temperatura de aquecimento e do tempo, pode ocorre a hidrólise da molécula resultando em seus monossacarídeos, que são os açúcares redutores.

O objetivo do teste era mostrar aos alunos que a não declaração correta nos rótulos de alimentos pode causar danos à saúde. Várias pessoas sofrem de diversas enfermidades como alergias, intolerâncias e diabetes. Para a maioria dos alimentos embalados, a rotulagem é o principal meio de comunicação pelo qual os fabricantes podem informar aos consumidores sobre a composição e a presença de alergênicos, permitindo a proteção à saúde dos indivíduos portadores de enfermidades. ${ }^{34}$

O emprego deste experimento propicia a contextualização no ensino de funções orgânicas (álcool, cetona, aldeído e ácido carboxílico), associando estas aos açúcares, que são comumente ingeridos em alimentos, e às reações de oxirredução. ${ }^{31,33}$ 
<smiles>O=CC(O)C(O)C(O)C(O)C(O)CO</smiles>

Glicose<smiles>O=CC(O)C(O)C(O)C(O)C(O)CO</smiles>

Galactose<smiles>O=C(C(O)CO)C(O)C(O)C(O)C(O)CO</smiles>

Frutose

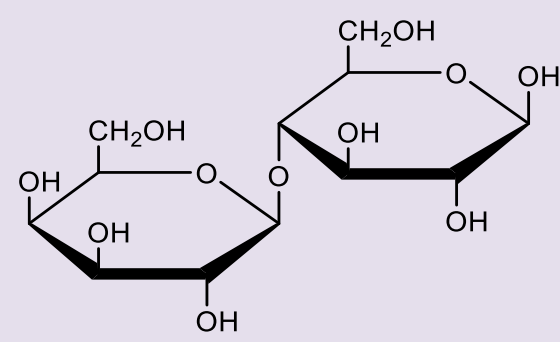

Lactose

Figura 8. Estrutura química dos açúcares redutores (glicose, galactose e frutose) e do dissacarídeo lactose

Com todas as análises realizadas, cada equipe preencheu seu laudo técnico, em que foi possível observar que todos os alunos conseguiram identificar as adulterações nas amostras de leite, solucionando o problema levantado pela história fictícia. Deste modo, os estudantes atuaram como analistas químicos ao preencherem e formularem suas próprias conclusões nos laudos técnicos decorrentes da coleta e análise dos dados. Quando os educandos são levados a investigar uma situação realizando experimentos dentro de um determinado contexto, passam a raciocinar melhor acerca das repostas, aprendem a formular hipóteses, e dessa forma, tornam-se sujeitos ativos no seu processo de aprendizagem. Uma atividade experimental baseada em situações-problema deve induzir no aprendiz uma curiosidade cada vez maior e o desenvolvimento do pensamento reflexivo e crítico. ${ }^{18,35}$ Abaixo encontram-se algumas conclusões obtidas nos laudos feitos pelos alunos.

"Concluímos que nenhum dos leites integrais testados estavam aptos para o consumo, pois $O A$ continha amido, $O B$ peróxido de hidrogênio, o $C$ não tinha lactose e o D tinha água." (grupo 1)

"Concluímos que todas as amostras estavam contaminadas, menos a referência e não recomendamos para o consumo." (grupo 2)

Os alunos alcançaram resultados muito satisfatórios, pois os experimentos além de motivar, auxiliaram na compreensão dos conceitos químicos, relacionando-os com a realidade dos alunos, tornando possível o entendimento dos fenômenos químicos microscópicos, a partir da visualização de fenômenos macroscópicos.

\subsection{Avaliação da metodologia e grau de} aprendizagem

O questionário aplicado mostrou, dentre outros parâmetros, o perfil dos alunos que participaram do curso. Em sua maioria (75 \%) eram do sexo feminino, todos estudantes do ensino médio (27,8\% cursavam o 1 ㅇan ano, $50 \%$ o 20 ano e $22,2 \%$ o 3ㅇ ano) e faixa etária variando entre 16 e 20 anos de idade (50\% com 17 anos, 22,2 \% tinham 16 anos; 19,4 \% com 15 anos e $8,4 \%$ entre 18 a 20 anos).

No questionário buscou-se saber se os alunos já haviam participado de alguma aula experimental ou realizado algum experimento envolvendo alimentos. A maioria (66,7 \%) afirmou que não, enquanto que o restante relatou já ter participado de aulas práticas na 
disciplina de Biologia, envolvendo a temática alimentos. Este dado reforça a importância do uso desta metodologia no ensino de Química, proporcionando aos alunos uma proposta contextualizada e interdisciplinar da experimentação investigativa.

$\mathrm{Na}$ segunda pergunta do questionário muitos alunos afirmaram que gostaram desse tipo de experimento, e que a prática despertou o interesse destes ao ponto de mencionarem que ficarão mais atentos aos rótulos dos alimentos que consomem. A temática favoreceu uma maior participação dos alunos durante a aula contextualizada que antecedeu a experimentação, de forma a se sentirem inseridos no assunto abordado. Segundo Oliveira et al (2011), ${ }^{36}$ a realização de uma aula experimental também permite aos alunos confirmarem os conteúdos vistos e terem conhecimento da aplicação da Química, além de tornar as aulas mais atrativas quando comparadas as aulas tradicionais.

Desta maneira, a utilização de atividades experimentais no ensino de Química demonstra uma grande importância no processo de ensino-aprendizagem. A experimentação é motivadora, instigante e permite a participação ativa dos estudantes. ${ }^{18,37,38}$

Foi questionado também sobre quais assuntos direcionados a Química haviam sido assimilados com a realização dos testes investigativos. A maioria (65\%) dos alunos conseguiram assimilar, principalmente, o conceito de densidade. Segundo Rossi $(2008)^{39}$ muitos estudantes apresentam dificuldades em aprender o conceito densidade na disciplina de Química. No entanto, observou-se que a experimentação investigativa desenvolvida neste trabalho proporcionou aos estudantes o entendimento desse conceito, provavelmente por terem conseguido visualizá-lo de forma prática em associação com o observado no dia a dia.

Além disso, os alunos ainda apontaram assuntos como cinética química (15\%) e reações químicas (15 \%) e apenas 5,0 \% mencionaram oxidação e redução. Este último conteúdo, supõe-se que os educandos associaram a reações químicas, pois o experimento apresentava uma mudança de coloração. Entendendo apenas que reagindo $A+B$ produzirá $C$, mas não compreenderam como ocorre o processo. Segundo Klein e Braibante $(2017)^{37}$ os alunos apresentam dificuldades na aprendizagem deste conteúdo, assim como na identificação dos agentes oxidantes e redutores, na transferência de elétrons e no número de oxidação.

Em seguida, foi questionado sobre a importância de conhecer a qualidade dos alimentos consumidos. De forma unânime, eles demonstraram preocupação em saber a qualidade dos alimentos que consomem. Isso é confirmado através de alguns relatos apresentados a seguir:

"Sabendo da qualidade, da origem e das substâncias dos alimentos podemos prevenir diversas reações adversas ao nosso organismo." (Aluno 1)

"Às vezes compramos produtos confiando na sua qualidade, mas na verdade estamos sendo enganados $e$ podendo causar problemas como alergia ou irritação." (Aluno 2)

"Não considerava muito, a única coisa que olhava era a data de validade, depois da aula vou procurar me preocupar com isso." (Aluno 3)

Além disso, buscou-se conhecer a opinião dos alunos com relação as dificuldades na realização dos testes investigativos. A grande maioria (94 \%) respondeu não haver encontrado dificuldades. Este dado reforça que os experimentos foram simples e podem ser reproduzidos nas escolas. Apenas $6 \%$ sentiram alguma dificuldade na atividade experimental, os quais eram alunos do 10 ano do Ensino Médio e ainda não haviam estudado alguns assuntos abordados nos experimentos. 
Através da experimentação investigativa, os alunos participaram ativamente do seu próprio processo de aprendizagem, além de ter proporcionado uma motivação maior, aguçado o interesse e a curiosidade e, sobretudo, promovido uma mudança de concepções sobre a alimentação, rotulagem e fiscalização de alimentos.

\section{Conclusão}

As atividades experimentais investigativas no ensino de Química visam a participação ativa dos alunos no processo educativo. 0 experimento investigativo e contextualizado envolvendo possíveis fraudes no leite relatado neste trabalho, baseou-se nos métodos de fiscalização aplicados na ANVISA e os possíveis tipos de fraudes recorrentes no país. Através de uma história fictícia os alunos puderam vivenciar uma das atividades realizadas pelos agentes da vigilância sanitária, abordando a fiscalização do leite. De modo geral, os alunos conseguiram identificar os contaminantes presentes nas amostras adulteradas, através das observações descritas no laudo técnico preenchido por eles.

A contextualização foi utilizada como uma ferramenta de aproximação entre o conhecimento químico adquirido e as situações presentes no cotidiano dos estudantes. A aula ministrada de forma contextualizada propiciou o interesse, a motivação e a curiosidade dos alunos, de modo que todos participaram das discussões levantadas em sala e se sentiram inseridos dentro do assunto.

Outra vantagem desta atividade para o Ensino de Química foi à possibilidade de torná-la interdisciplinar com a disciplina de Biologia, visto que a temática da composição dos alimentos, atreladas a qualidade de vida possuem estreita relação com os assuntos voltados a Biologia. Além dos impactos positivos no ensino-aprendizagem da Química decorrentes do envolvimento maior dos alunos com a investigação, essa proposta também permitiu a formação de um pensamento crítico acerca da importância da rotulagem e qualidade dos alimentos.

\section{Agradecimentos}

Os autores agradecem o apoio financeiro da CAPES, CNPq e FUNCAP.

\section{Referências Bibliográficas}

${ }^{1}$ Costa, A. A. F.; Souza, J. R. T. Obstáculos no processo de ensino e de aprendizagem de cálculo estequiométrico. Amazônia. Revista de Educação em Ciências e Matemática 2013, 10, 106. [Crossref]

${ }^{2}$ Pazinato, M. S.; Braibante, M. E. F. Oficina Temática Composição Química dos Alimentos: Uma Possibilidade para o Ensino de Química. Química Nova na Escola 2014, 36, 289. [Crossref]

${ }^{3}$ Silva, V. G. D. A Monografia de Graduação. Universidade Estadual Paulista, 2016. [Link]

${ }^{4}$ Leite, F. F. Química e o Cotidiano. Scientia Cum Industria 2015, 3, 117. [Crossref]

${ }^{5}$ Cunha, M. B. O Glúten em Questão. Química Nova na Escola 2018, 40, 59. [Crossref]

${ }^{6}$ Oliveira, R. J. Ensino de Química: Por Um Enfoque Epistemológico e Argumentativo. Química Nova na Escola 2015, 37, 257. [Crossref]

${ }^{7}$ Cruz, A. A. C.; Ribeiro, V. G. P.; Longhinotti, E.; Mazzetto, S. E. A Ciência Forense no Ensino de Química por Meio da Experimentação Investigativa e Lúdica. Química Nova na Escola 2016, 38, 167. [Crossref]

${ }^{8}$ Silva, R. M. G. D. Contextualizando aprendizagens em química na formação escolar. Química Nova na Escola 2003, 18, 26. [Link]

${ }^{9}$ Brasil. Base Nacional Comum Curricular: Ensino Médio. Ministério da Educação. Secretaria de Educação Média e Tecnológica. 
Disponível

<http://basenacionalcomum.mec.gov.br/aba se/\#medio > Acesso em: 30 maio 2019.

${ }^{10}$ Fernandes, C. D. S.; Marques, C. A. Noções de Contextualização nas Questões Relacionadas ao Conhecimento Químico no Exame Nacional do Ensino Médio. Química Nova na Escola 2015, 37, 294. [Crossref]

${ }^{11}$ Wartha, E. J.; Silva, E. L. D.; Bejarano, N. R. R. Cotidiano e Contextualização no Ensino de Química. Química Nova na Escola 2013, 35, 84. [Crossref]

${ }^{12}$ Coelho, J. C.; Marques, C. A. A Chuva Ácida na Perceptiva de Tema Social: Um Estudo com Professores de Química. Química Nova na Escola 2007, 25, 14. [Link]

13 Santos, W. L. P.; Contextualização no Ensino de Ciências por meio de temas CTS em uma perspectiva crítica. Ciência \& Ensino 2007, número especial, 1. [Link]

${ }^{14}$ Marcondes, M. E. R.; Carmo, M. P.; Suart, R. C.; Silva, E. L.; Souza, F. L.; Santos Jr, J. B.; Akahoshi, L. H. Materiais Instrucionais numa perspectiva CTSA: Uma análise de unidades didáticas produzidas por professores de Química em formação continuada. Investigações em Ensino de Ciências 2009, 14, 281. [Link]

${ }^{15}$ Neves, A. P.; Guimarães, P. I. C.; Merçon, F. Interpretação de Rótulos de Alimentos no Ensino de Química. Química Nova na Escola 2009, 31, 34. [Link]

${ }^{16}$ Agência Nacional de Vigilância Sanitária (ANVISA). Resolução - RDC № 360, de 23 de dezembro de $2003 . \quad$ Disponível em: <http://portal.anvisa.gov.br/ documents/33880/2568070/res0360_23_12_ 2003.pdf/5d4fc713-9c66-4512-b3c1afee57e7d9bc>. Acesso em: 16 fevereiro 2017.

${ }^{17}$ Guimarães, C. C. Experimentação no Ensino de Química: Caminhos e Descaminhos Rumo à Aprendizagem Significativa. Química Nova na Escola 2009, 31, 198.

${ }^{18}$ Souza, F. L.; Akahoshi, L. H.; Marcondes, M. E. R.; Carmo, M. P. Atividades experimentais investigativas no ensino de química. Cetec capacitações: Projeto de formacão continuada de professores da educacão profissional do Programa Brasil Profissionalizado - Centro Paula Souza Setec/MEC, 2013. [Link]

${ }^{19}$ Ferreira, L. H.; Hartwig, D. R.; Oliveira, R. C. D. Ensino Experimental de Química: Uma Abordagem Investigativa Contextualizada. Química Nova na Escola 2010, 32, 101. [Link]

${ }^{20}$ Machado, P. F. L.; Mól, G. D. S. Experimentando Química com Segurança. Química Nova na Escola 2008, 27, 57. [Link]

21 Zômpero, A. F.; Laburú, C. E. Implementação de atividades investigativas na disciplina de ciências em escola pública: uma experiência didática. Investigações em Ensino de Ciências 2012, 17, 675. [Link]

22 Brasil. Agência Nacional de Vigilância Sanitária. RELATÓRIO DE ATIVIDADES 2017 / Agência Nacional de Vigilância Sanitária. Brasília: ANVISA, 2018. [Link]

${ }^{23}$ Sítio da Agência Nacional de Vigilância Sanitária (ANVISA). Disponível em: <http://portal.anvisa.gov.br/>. Acesso: 20 Junho 2017.

${ }^{24}$ Agência Nacional de Vigilância Sanitária (ANVISA). Fiscalização de Alimentos, 2016. [Link]

${ }^{25}$ Bolzan, R. C.; Bromatologia. Frederico Westphalen: Universidade Federal de Santa Maria, Colégio Agrícola de Frederico Westphalen, 2013. [Link]

${ }^{26}$ Agência Nacional de Vigilância Sanitária. Intolerância à lactose - Rotulagem de lactose em alimentos tem regra publicada, 2017. [Link]

${ }^{27}$ Abrantes, M. R.; Campêlo, C. D. S.; Silva, J. B. A. D. Fraude em leite: Métodos de detecção e implicações para o consumidor. Revista Instituto Adolfo Luiz 2014, 73, 244. [Crossref]

28 Teixeira, L. V. Análise Sensorial na Indústria de Alimentos. Revista do Instituto de Laticínios Cândido Tostes 2009, 366, 12. [Link]

${ }^{29}$ Souza, P. V. T.; Silva, M. D.; Amauro, N. Q.; Mori, R. C.; Moreira, P. F. S. D. Densidade: uma 
proposta de aula investigativa. Química Nova na Escola 2015, 37, 120. [Crossref]

${ }^{30}$ Mareze, J.; Marioto, L. R. M.; Gonzaga, N.; Daniel, G. C.; Tamanini, R.; Beloti, V. Deteç̧ão de adulterações do leite pasteurizado por meio de provas oficiais. Semina: Ciências Biológicas e da Saúde 2015, 36, 283. [Crossref]

${ }^{31}$ Francisco Junior, W. E. Carboidratos: Estrutura, Propriedades e Funções. Química Nova na Escola 2008, 29, 8. [Link]

${ }^{32}$ Scherer, T.; Monografia de Conclusão de Curso, Centro Universitário UNIVATES, Brasil, 2015. [Link]

${ }^{33}$ Oliveira, R. O.; Maria, L. C. S.; Merçon, F.; Aguiar, M. R. M. P. Preparo e Emprego do Reagente de Benedict na Análise de Açúcares: Uma proposta para o Ensino de Química Orgânica. Química Nova na Escola 2006, 23, 41. [Link]

${ }^{34}$ Agência Nacional de Vigilância Sanitária (ANVISA). Perguntas e Respostas - Rotulagem de Alimentos Alergênicos, 2017. [Link]
${ }^{35}$ Francisco Junior, W. E.; Ferreira, L. H.; Hartwig, D. R. Experimentação Problematizadora: Fundamentos Teóricos e Práticos para a Aplicação em Salas de Aula de Ciências. Química Nova na Escola 2008, 30, 34. [Link]

${ }^{36}$ Oliveira, C. A. F. D.; Resende Filho, J. B. M. D. R.; Andrade, L. R. D. Identificação de Ácido Salićlico em Produtos Dermatológicos Utilizando-se Materiais Convencionais. Química Nova na Escola 2011, 33, 125. [Link]

${ }^{37}$ Klein, S. G.; Braibante, M. E. F. Reações de oxi-redução e suas diferentes abordagens. Química Nova na Escola 2017, 39, 35. [Link]

${ }^{38}$ Giordan, M. O papel da Experimentação no ensino de ciências. Química Nova na Escola 1999, 10, 43. [Link]

${ }^{39}$ Rossi, A. V. ; Massaroto, A. M.; Garcia, F. B. T.; Anselmo, G. R. T.; De Marco, I. L.G.; Curralero, I. C. B.; Terra, J.; Zanini, S. M. C. Reflexões sobre o que se Ensina e o que se Aprende sobre Densidade a partir da Escolarização. Química Nova na Escola 2008, 30, 55. [Link] 